\title{
Pretreatment Effect of Alcoholic Olive Leaf Extract on Oxidative and Antioxidative Enzymes Status in Ovariectomized Rats
}

\author{
Mohammadreza Nasirzadeh $^{1^{*}}$, Arash Rasouli ${ }^{2}$
}

\begin{abstract}
Objectives: Menopause with oxidative imbalance causes metabolic disorders. These disorders are involved in the pathogenesis of various diseases. Olive leaf is a rich source of phenolic compounds that are biologically active and have better antioxidant activity, anti-inflammatory and radical scavenging effect. The aim of this study was to evaluate the effects of olive leaf extract on antioxidant activity of liver tissue in ovariectomized rats.

Materials and Methods: In this study, 21 male Wistar rats weighting $220 \pm 20$ g were randomly selected and were divided into three groups ( $n=7)$ : 1) control group (healthy animals), 2) OVX group (ovaries removed by surgery) and 3) OVX-OLE group (ovaries removed and received olive leaf extract). The third group of animals received olive leaf extract for 30 days in dose of $100 \mathrm{mg} / \mathrm{kg}$ orally and through gavages. At the end of the study, samples of liver tissue were taken and the activities of super oxide dismutase (SOD), glutathione peroxidase (GPX), malondialdehyde (MDA) and catalase were measured.

Results: The results showed that ovariectomy reduced rates of SOD $(P=0.001), \operatorname{GPX}(P=0.003)$ and catalase $(P=0.001)$ significantly compared to controls. It was also found that the average level of MDA in OVX group than the OVX-OLE and control group was significantly higher $(P=0.001)$.

Conclusion: This study showed that oral administration of olive leaf can increase the activity of antioxidant enzymes in the liver tissue.

Keywords: Liver, Olea, Ovariectomy, Rats
\end{abstract}

\section{Introduction}

There is increasing evidence that menopause due to oxidative imbalance will lead to metabolic disorders (1). Menopause also increases food intake and body weight gain and is associated with abnormalities in lipid metabolism (2). More recent experimental studies confirm that ovariectomy cause oxidative stress and cell damage in animals $(1,3,4)$. Steroid hormones, particularly estrogen, are natural antioxidants (5). Hormonal balance is a critical factor for the appropriate activity of the body organs. Any hormonal imbalances lead to impaired metabolic processes. Such an imbalance can be shown by changes in the oxidant/antioxidant status in the liver (1). Estradiol and its derivatives can reduce lipid peroxidation in serum and liver tissue and can also increase expression of antioxidant enzymes such as super oxide dismutase (SOD) and glutathione peroxidase (GPX) (6). Lipid peroxidation in biological membranes is extremely damaging and occurs when reactive oxygen species and free radicals attack the double bonds of unsaturated fatty acids. These compounds are toxic and if not removed, can create a chain of reactions (7).

Ovariectomy in rats is a common method to evaluate the effects of estrogen loss in animal models. The lack of es- trogen is associated with increased food intake and weight of the animal (6). Research on flavonoids and other polyphenols with antioxidant properties due to their biological activities and their effects on the prevention of the disease is increasing (8).

Olive leaf as a rich source of biologically active phenolic compounds have better antioxidant activity, anti-inflammatory power and radical scavenging effects $(9,10)$. Flavonoids are the most widespread polyphenolic compounds that as antioxidant compounds have been identified in various biological systems in recent years. Olive tree leaves as an ancient remedy were used in Europe and the Mediterranean diet in the form of herbal tea and extract. It seems that olive leaf extract with phenolic compounds can be used as natural antioxidants (11). Therefore, the aim of this study was to evaluate the effects of olive leaf extract on antioxidant activity of liver tissue in ovariectomized rats.

\section{Materials and Methods}

In this study, 21 male Wistar rats weighting $220 \pm 20 \mathrm{~g}$ were randomly selected and divided into three groups. Rats were provided from the Center of Laboratory Animal husbandry and Veterinary Medicine, Tabriz Azad University. The rats were kept under similar conditions with free 
access to food and water, temperature $22 \pm 2^{\circ} \mathrm{C}$ and $12 / 12$ light-dark cycle. All animals were treated in accordance to the Principles of Laboratory Animal Care [NIH]. Animals were divided into three groups $(n=7): 1)$ control group (healthy intact animals), 2) OVX group (bilateral ovariectomy surgery) and 3) OVX-OLE group (ovariectomized animals that received olive leaf extract).

\section{Extraction}

After collecting the leaves of olive (Olea europaea L.) from gardens of northern Iran in summer and confirmation by the Department of Horticultural Science, Islamic Azad University, Tabriz, leaves were dried in the shade. In order to provide olive leaf extract, $200 \mathrm{~g}$ fresh olive leaf after drying, was grinded into powder and then the extraction was performed using $80 \%$ ethanol. After evaporation of solvent using a rotary evaporator, the remainder of the extract was administered orally (12). Two weeks after surgery, OVX-OLE group received olive leaf extract with dose of $100 \mathrm{mg} / \mathrm{kg}$ body weight in $0.5 \mathrm{~mL}$ normal saline by gavages for 30 days (13). Rats in the control and OVX groups received $0.5 \mathrm{~mL}$ normal saline orally.

\section{Surgery}

To create anesthesia in animals' ketamine $40 \mathrm{mg} / \mathrm{kg}$ and xylazine $10 \mathrm{mg} / \mathrm{kg}$ of body weight was used (9). To remove the ovaries on each side, a longitudinal incision on the dorsolateral side was given and after access to the ovary, upper part of oviduct and lower part of ovary was ligatured by polyglycolide and ovaries were removed.

Prepare Tissue for Measuring Antioxidant Enzymes Rat liver was thawed and manually homogenized in cold phosphate buffer. After centrifugation the supernatant was removed and serum enzymes were measured by the standard commercial kits.

Measurement of Super Oxide Dismutase Activity The unit of SOD activity was expressed as some of the sample that will catalyze $1 \mu$ mole of superoxide radicals to hydrogen peroxide and oxygen in one minute. SOD activity was determined colorimetrically at $420 \mathrm{~nm}$.

Measurement of Glutathione Peroxidase Activity In this method, the GPX activity unit was expressed as some of the sample that will catalyze $1 \mu$ mole GSH to GSSG in one minute. GPX activity was determined calorimetrically at $412 \mathrm{~nm}$.

\section{Measurement of Catalase Activity}

The catalase activity unit was considered as some of the sample that will catalyze $1 \mu$ mole of hydrogen peroxide to water and oxygen in one minute. Catalase activity was determined colorimetrically at $405 \mathrm{~nm}$.

Measurement of Malondialdehyde

The amount of lipid peroxidation was determined by thiobarbituric acid reactive substances (TBARS) in the liver. MDA activity was determined colorimetrically at $532 \mathrm{~nm}$.
All parameters have been evaluated using diagnostic Zell Bio kits and according to the manufactures instructions (Zell Bio, Germany).

\section{Results}

Survey of data showed that there was no significant difference between studied groups in weight of the animals at the beginning of the period $(P>0.05)$; while weight of animals of OVX group was significantly increased at the end of the period $(P=0.046)$. Also there was no significant different between OVX and OVX-OLE groups $(P>0.05$; Figure1). Statistical comparison of mean of antioxidant enzymes namely SOD $(P=0.001)$, GPX $(P=0.003)$ and catalase $(P=0.001)$ indicated that there were significant differences between OVX, OVX-OLE and control groups. However there were not significant differences between control and OVX-OLE groups (Figures $2-4 ; P>0.05$ ). In addition, comparison of MDA data in studied groups indicated that the average level of MDA in OVX group was higher than the OVX-OLE and control groups significantly $(P=0.001)$. There was no significant difference between OVX and OVX-OLE groups (Figure 5; $P>0.05$ ).

\section{Discussion}

In this study the pretreatment effect of alcoholic olive leaf extract on liver antioxidant enzymes in ovariectomized rats was evaluated. The results showed clearly positive effects of olive leaf extract in the prevention of lipid peroxidation and reduced antioxidant enzyme activity. The results showed that the mean body weight in ovariecto-

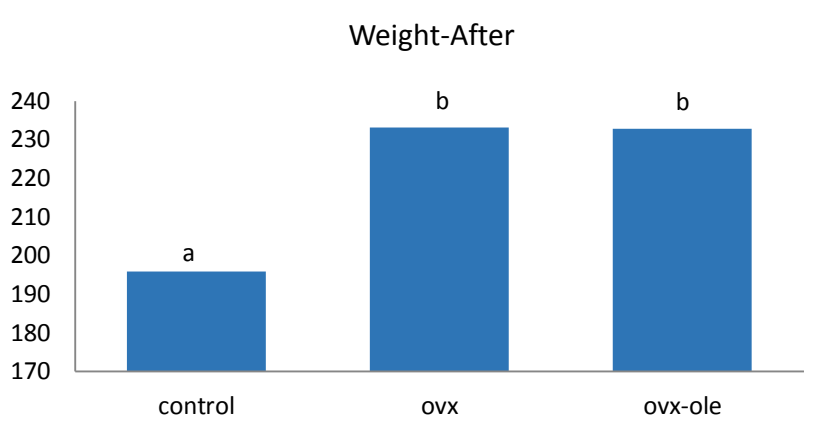

Figure 1. Weight of Animals in Study at the End of the Period (Mean \pm SEM).

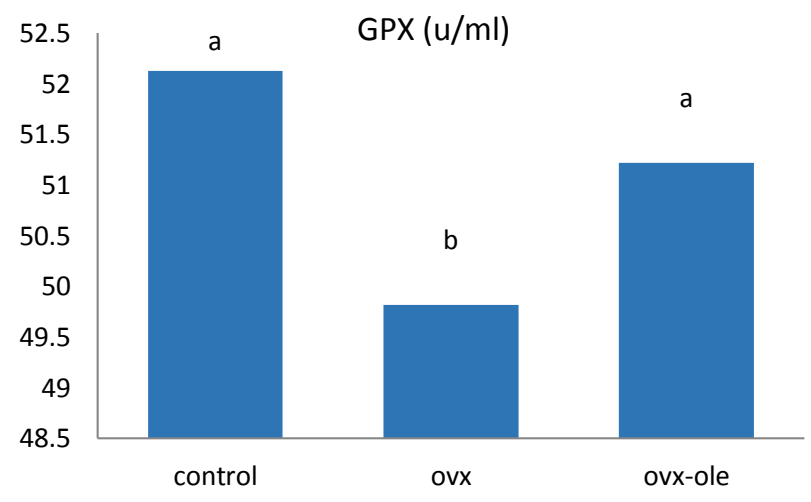

Figure 2. GPX Mean Levels in Liver Tissue in Different Studied Groups (Mean \pm SEM). 


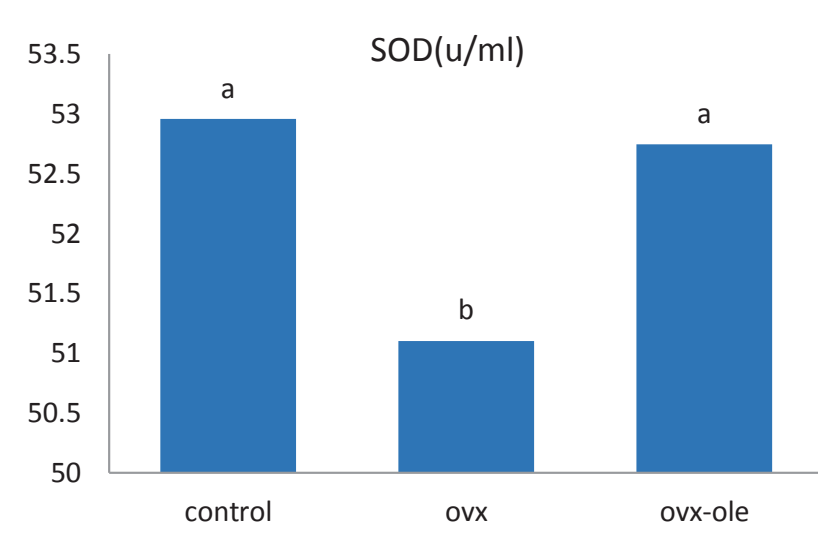

Figure 3. SOD Mean Levels in Liver Tissue in Different Studied Groups (Mean \pm SEM).

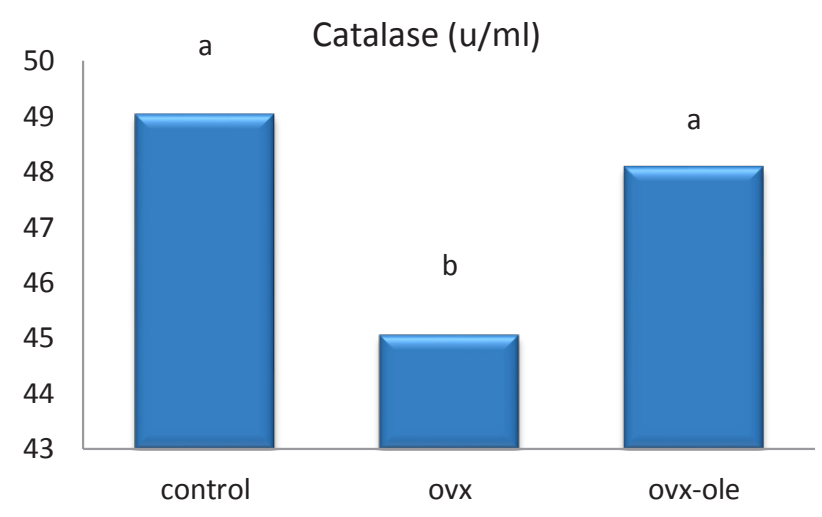

Figure 4. Catalase Mean Levels in Liver Tissue in Different Studied Groups (Mean \pm SEM).

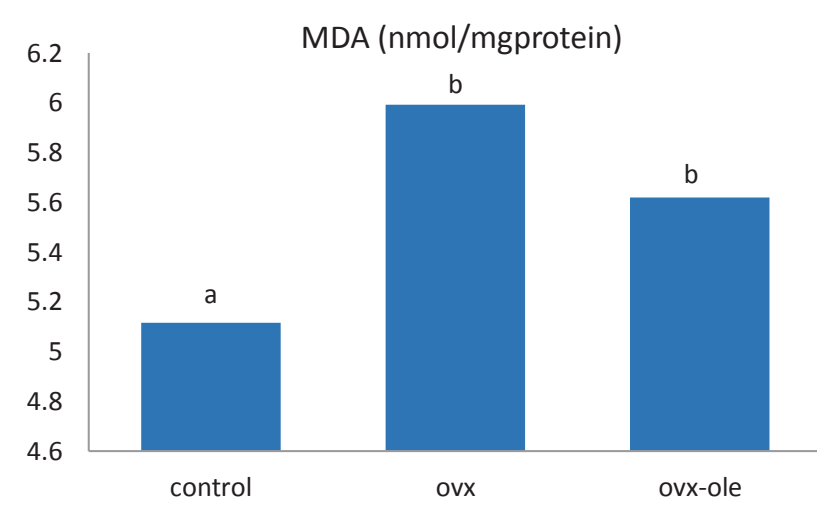

Figure 5. MDA Mean Levels in Liver Tissue in Different Studied Groups (Mean \pm SEM).

mized rats compared with the control group significantly increased. These results agree with previous studies that weight gain is caused by lack of hormonal correspond $(1,14)$. It is well known that weight gain occurs in postmenopausal women. It is thought this process occurs through interaction with leptin. Leptin is produced by fat cells and contribute in the regulation of body weight and appetite (15). The results of animals' weights showed that there was no significant difference between OVX and OVX-OLE groups. That is, the oral administration of the extract for 30 days could not prevent weight gain in ovariectomized rats. Fat accumulation and excessive free fat- ty acids in non-fatty tissues such as liver, kidney, heart, skeletal muscle and blood vessels is mainly caused by cell dysfunction and cell death due to lipotoxicity (16).

Miller et al showed that the use of phenolic compounds in the diet has main role in weight management with reduced disease risk in postmenopausal women and can help to prevent lipotoxicity in women with fatty liver disease (17). Menopause is associated with an increase in free radicals that leads to dysfunction in some of the organs. Several studies have shown that estrogen loss naturally or by surgery increases the risk of metabolic diseases. Antioxidant effects of estrogens as the main mechanism of protection against oxidative damage are considerable in liver and pancreas (5). In women with breast cancer who are treated with tamoxifen (estrogen antagonist), increase of intra-abdominal fat and incidence of liver disease are seen (18).

Hernández et al have shown that ovariectomy causes significant reduction in total antioxidant status (TAS) and significant increase in the amount of MDA in rats $(1,19)$. The results of our study are consistent with these findings as detected in ovariectomized rats compared with the control group; the activity level of enzymes SOD and GPX are significantly reduced. Meanwhile the amount of MDA in liver tissue in ovariectomized rats significantly increased compared to the control group. Also it was found that the activity levels of SOD, GPX and catalase between OVXOLE and control groups were not significantly different. In the other words, oral administrations of olive leaf extract in ovariectomized rats improved these parameters. Olive leaves contain polyphenolic compounds such as oleuropein and flavonoids triterpenes which are protective against oxidative stress (20). Alirezaei et al in 2012 reported that oleuropein can suppress oxidative stress in the liver tissue as it can reduce lipid peroxidation in the rat liver. Oleuropein, a natural phenolic antioxidant compound is found in high concentrations in olive leaf (7). Also, Yoon et al in 2014 reported that olive leaf extract in the ovariectomized rats can regulate expression of genes involved in lipid metabolism. In recent study, the extract with doses of $200 \mathrm{mg} / \mathrm{kg}$ or $400 \mathrm{mg} / \mathrm{kg}$ for 16 weeks was consumed (2). In the present study, liver MDA level in OVX-OLE group compared with OVX group decreased, but the decrease was not significant.

\section{Conclusion}

The results of this study showed that oral administration of olive leaf extract can reduce the lipid peroxidation and increase activity of antioxidant enzymes in ovariectomized rats; thereby protecting the liver tissue against oxidative damage induced by ovariectomy.

\section{Ethical Issues}

Ethical clearance for the study was obtained from the ethics committee of Islamic Azad University.

\section{Conflict of Interests}

The authors declare no conflict of interests. 


\section{Financial Support}

The researchers received no financial support or grant from any funding agency in the public and commercial sectors.

\section{Acknowledgments}

The authors would like to thank the Faculty of Veterinary Medicine, Islamic Azad University, Tabriz Branch, Tabriz, Iran.

\section{References}

1. Al-Rejaie SS. Thymoquinone treatment alleviate ovariectomy-induced hepatic oxidative damage in rats. J Applied Pharm Sci. 2013;3(6):126-131.

2. Yoon L, Liu Y, Kim HS. Effect of olive leaf extract on the gene expression for lipid metabolism in ovariectomized rats. FASEB J. 12014;28(Suppl 1):814816.

3. 3. Muñoz-Castañeda JR, Muntané J, Herencia $\mathrm{C}$, et al. Ovariectomy exacerbates oxidative stress and cardiopathy induced by adriamycin. Gynecol Endocrinol. 2006;22(2):74-79. doi:10.1080/09513590500490249.

4. Muthusami S, Ramachandran I, Muthusamy B, et al. Ovariectomy induces oxidative stress and impairs bone antioxidant system in adult rats. Clin Chim Acta. 2005;360(1-2):81-86. doi:10.1016/j.cccn.2005.04.014.

5. Cay M, Ulas M. Effects of estrogen replacement therapy with vitamin $\mathrm{E}$ on oxidative stress in hepatic and pancreatic tissues of ovariectomized diabetic rats. J Anim Vet Adv. 2010;9(23):2955-2962. doi:10.1016/j. cccn.2005.04.014.

6. Vuković R, Blažetić S, Oršolić I, et al. Impact of ovariectomy, high fat diet, and lifestyle modifications onoxidative/antioxidative status in the rat liver. Croat Med J. 2014;55(3):218-227. doi:10.3325/ cmj.2014.55.218.

7. Alirezaei M, Dezfoulian O, Kheradmand A, Neamati S, Khonsari A, Pirzadeh A. Hepatoprotective effects of purified oleuropein from olive leaf extract against ethanol-induced damages in the rat. Iranian J Vet Res. 2012;13(3):218-226.

8. Dekanski D, Janicijevic-Hudomal S, Tadic V, Markovic G, Arsic I, Mitrovic DM. Photochemical analysis and gastro protective activity of an olive leaf extract. J Serb Chem Soc. 2009;74(4):367-377. doi:10.3325/cmj.2014.55.218.

9. Omar SH. Cardio protective and neuroprotective roles of oleuropein in olive. Saudi Pharm J 2010;18(3):111-
121. doi:10.1016/j.jsps.2010.05.005.

10. Lee $\mathrm{OH}$, Lee BY, Lee J, et al. Assessment of phenolics-enriched extract and fractions of olive leaves and their antioxidant activities. Bioresource Technol. 2009;100(23):6107-6113. doi:10.1016/j. biortech.2009.06.059.

11. Lee $\mathrm{OH}$, Lee BY. Antioxidant and antimicrobial activities of individual and combined phenolics in Olea europaea leaf extract. Bioresour Technol. 2010;101(10):3751-3754. doi:10.1016/j. biortech.2009.12.052.

12. Tavafi $M$, Ahmadvand $H$, Toolabi P. Inhibitory effect of olive leaf extract on gentamicin-induced nephrotoxicity in rats. Iranian J Kidney Dis. 2012; 6:25-32.

13. Mohagheghi F, Bigdeli MR, Rasoulian B, Hashemi P, Pour MR. The neuroprotective effect of olive leaf extract is related to improved blood-brain barrier permeability and brain edema in rat with experimental focal cerebral ischemia. Phytomedicine. 2011;18(23):170-175. doi:10.1016/j.phymed.2010.06.007.

14. Choi MJ. Effects of taurine supplementation on bone mineral density in ovariectomized rats fed calcium deficient diet. Nutr Res Pract. 2009;3(2):108-113. doi:10.4162/nrp.2009.3.2.108.

15. Gao Q, Horvath TL. Cross-talk between estrogen and leptin signaling in the hypothalamus. Am J Physiol Endocrinol Metab. 2008;294(5):817-826. doi:10.1152/ ajpendo.00733.2007.

16. Oluba OM, Onyeneke EC, Ojieh GC, Eidangbe GO. Effects of soy protein on selected enzymes in tissues of rats fed a cholesterol diet. Int J Med Med Sci. 2009;1(9):400-406.

17. Miller CN, Yang JY, Avra T, et al. A dietary phytochemical blend prevents liver damage associated with adipose tissue mobilization in ovariectomized rats. Obesity (Silver Spring). 2015;23(1):112-119. doi:10.1002/oby.20907.

18. Rodrigues MF, Stotzer US, Domingos MM, et al. Effects of ovariectomy and resistance training on oxidative stress markers in the rat liver. Clinics (Sao Paulo). 2013;68(9):1247-1254.

19. Hernández I, Delgado JL, Díaz J, Quesada T, Teruel MG, Llanos MC. 17 $\beta$-Estradiol prevents oxidative stress and decreases blood pressure in ovariectomized rats. Am J Physiol Regul Integr Comp Physiol. 2000;279(5):1599-1605.

20. Turkez H, Togar B, Polat E. Olive leaf extract modulates permethrin induced genetic and oxidative in rats. Cytotechnology. 2010;64(4):459-464.

Copyright $\odot 2016$ The Author(s); This is an open-access article distributed under the terms of the Creative Commons Attribution License (http://creativecommons.org/licenses/by/4.0), which permits unrestricted use, distribution, and reproduction in any medium, provided the original work is properly cited. 